\title{
Refining the role of pegfilgrastim (a long-acting G-CSF) for prevention of chemotherapy-induced febrile neutropenia: consensus guidance recommendations
}

\author{
Matti Aapro $^{1} \cdot$ Ralph Boccia $^{2} \cdot$ Robert Leonard $^{3} \cdot$ Carlos Camps $^{4} \cdot$ Mario Campone $^{5}$. \\ Sylvain Choquet ${ }^{6} \cdot$ Marco Danova $^{7} \cdot$ John Glaspy $^{8}$ - Iwona Hus ${ }^{9} \cdot$ Hartmut Link $^{10}$. \\ Thamer Sliwa ${ }^{11} \cdot$ Hans Tesch $^{12} \cdot$ Vicente Valero $^{13}$
}

Received: 31 March 2017 / Accepted: 24 July 2017 / Published online: 25 August 2017

(C) The Author(s) 2017. This article is an open access publication

\begin{abstract}
Purpose Chemotherapy-induced febrile neutropenia (FN) causes treatment delays and interruptions and can have fatal consequences. Current guidelines provide recommendations on granulocyte colony-stimulating factors (G-CSF) for prevention of $\mathrm{FN}$, but guidance is unclear regarding use of shortvs long-acting G-CSF (e.g., filgrastim vs pegfilgrastim/ lipegfilgrastim, respectively). An international panel of experts convened to develop guidance on appropriate use of pegfilgrastim for prevention of chemotherapy-induced $\mathrm{FN}$.

Methods Guidance recommendations were developed following a literature review, survey, evaluation of current practice, and an expert meeting. Consensus was established using an anonymous Delphi-based approach.

Results Guidance recommendations for prevention of treatment-associated FN were as follows: for treatment with curative intent, maintenance of dose intensity using G-CSF to prevent dose delays/reduction should be standard of care;
\end{abstract}

Matti Aapro

maapro@genolier.net

1 Cancer Center, Clinique de Genolier, Route du Muids 3, 1272 Genolier, Vaud, Switzerland

2 Center for Cancer and Blood Disorders, P.C., Bethesda, MD, USA

3 Division of Cancer, Imperial College London, London, UK

4 Department of Medical Oncology, Hospital General Universitario de Valencia, València, Spain

5 Department of Medical Oncology, Institut de Cancérologie de l'Ouest, Angers, France

6 Service d'Hématologie Clinique, Hôpital de la Pitié Salpêtrière, Paris, France for treatment-associated FN risk $\geq 20 \%$, short-acting G-CSF/ pegfilgrastim should be given from cycle 1 onwards; and for treatment-associated FN risk $<20 \%$, short-acting G-CSF/ pegfilgrastim should be given if factors suggest overall risk (including treatment-related and patient-related risk factors) is $\geq 20 \%$. It was agreed that pegfilgrastim and 11 days' filgrastim have similar efficacy and safety and that pegfilgrastim is preferred to < 11 days' filgrastim (and may be preferred to $\geq 11$ days' filgrastim based on adherence and convenience); pegfilgrastim is not appropriate in weekly chemotherapy; in split-dose chemotherapy, pegfilgrastim is recommended $24 \mathrm{~h}$ after last chemotherapy dose; and during palliative chemotherapy, patient adherence and convenience may favor pegfilgrastim.

Conclusion In this era of targeted therapies, additional trials with G-CSF are still required. These recommendations should be used with existing guidelines to optimize pegfilgrastim use in clinical practice.
7 Internal Medicine and Medical Oncology Department, Ospedale Civile di Vigevano, Pavia, Vigevano, Italy

8 Department of Medicine, UCLA School of Medicine, Los Angeles, CA, USA

9 Department of Clinical Transplantology, Medical University of Lublin, Lublin, Poland

10 Department of Hematology and Oncology, West-Palatinate Clinical Centre, Kaiserslautern, Germany

11 Department of Hematology and Oncology, Hanusch Hospital, Vienna, Austria

12 Center for Hematology and Medical Oncology, Bethanien Hospital, Frankfurt, Germany

13 Department of Breast Medical Oncology, The University of Texas MD Anderson Cancer Center, Houston, TX, USA 
Keywords Chemotherapy-induced febrile neutropenia . Consensus guidance $\cdot$ Granulocyte colony-stimulating factors $\cdot$ Guidelines $\cdot$ Pegfilgrastim

\section{Introduction}

Febrile neutropenia (FN) is a serious side effect of many cancer treatments and can lead to infections and sepsis with potentially fatal consequences [1]. The European Society of Medical Oncology defines FN as "an oral temperature of $38.3{ }^{\circ} \mathrm{C}$ or two consecutive readings of $>38.0{ }^{\circ} \mathrm{C}$ for 2 hours and an absolute neutrophil count (ANC) of $<0.5 \times 10^{9} / \mathrm{L}$, or expected to fall below $<0.5 \times 10^{9} / \mathrm{L}$ " [2]. The Infectious Diseases Society of America defines it as an "ANC $<500$ cells $/ \mathrm{mm}^{3}$ (or that is expected to decrease to $<500$ cells/ $\mathrm{mm}^{3}$ during the next 48 hours) with a single oral temperature measurement of $>38.3{ }^{\circ} \mathrm{C}$ or a temperature of $\geq 38.0{ }^{\circ} \mathrm{C}$ sustained over a 1-hour period" [3]. In patients receiving chemotherapy, development of FN can result in dose reduction and/or treatment delays, or treatment discontinuation, which may limit disease control $[1,4]$.

The overall global incidence of FN is difficult to assess as events are not always identified or reported. Neutropenic hospitalizations, frequently associated with $\mathrm{FN}$, are simpler to quantify. US studies suggest an estimated 7.83 neutropenic hospitalizations per 1000 cancer patients each year $(60,294$ cases in 1999), with incidence increasing to 43.3 cases per 1000 patients in those with hematologic malignancies [5]. Evidence from clinical trials and clinical practice suggests the incidence of FN may be higher (up to 117 cases per 1000 patients) $[6,7]$.

Current guidelines recommend granulocyte colonystimulating factors (G-CSF) for primary prophylaxis of chemotherapy-induced FN when the overall risk of FN among patients with non-myeloid malignancies receiving myelosuppressive chemotherapy is $\geq 20 \%[1,2,8]$. In clinical trials and daily practice, primary and secondary prophylaxis with GCSF has been shown to reduce FN incidence and complications and improve outcomes of cancer treatment [1,9]. However, despite guideline recommendations, G-CSF primary prophylaxis remains underutilized in clinical practice $[10$, 11] and patients often receive inconsistent and suboptimal courses of G-CSF treatment $[12,13]$.

The majority of available G-CSF treatments are short-acting; however, the number of long-acting agents (e.g., pegfilgrastim and lipegfilgrastim) is increasing. Pegfilgrastim is the most widely approved long-acting G-CSF available worldwide. Initially approved in 2002, it is now the most commonly used and is associated with the most experience and clinical data. Lipegfilgrastim, which was approved in 2013, has more limited availability worldwide (primarily available in Europe) and, thus, there is less experience of its use $[14,15]$. In clinical trials and practice, pegfilgrastim has been shown to have a favorable efficacy and safety profile [14, 16-20] and may be preferred over short-acting G-CSF by both patients and physicians due to improved adherence and its convenient once-per-cycle subcutaneous administration.

Biosimilar products are biologic medicines that have highly similar physicochemical and functional characteristics; they must demonstrate a similar quality, efficacy, and safety profile to the reference biologic product [21]. G-CSF biosimilars are increasingly being used for prevention of chemotherapyinduced FN [22-24].

While current guidelines provide general recommendations on the use of G-CSF for prevention of chemotherapy-induced FN, they do not distinguish between the use of pegfilgrastim/ lipegfilgrastim and short-acting G-CSF in practice, nor do they provide guidance on the most appropriate patient profile for each agent. Guidance on the appropriate use of pegfilgrastim in particular situations and patient populations does not exist.

In November 2015, a group of experts in the management of chemotherapy-induced FN, with experience in solid tumors and hematologic malignancies, convened to develop a consensus document to direct the appropriate use of pegfilgrastim in clinical practice. The aim was to establish clear guidance recommendations on the appropriate use of pegfilgrastim for prevention of chemotherapy-induced $\mathrm{FN}$, considering different situations and patient populations encountered in clinical practice. This document is intended to complement the information provided in existing guidelines and provide clinically relevant suggestions for use in daily practice.

\section{Methods}

\section{Expert selection}

Experts were selected for participation in the advisory board if they were a specialist in oncology and/or oncohematology and had extensive clinical experience with both short-acting and long-acting G-CSF. They were also required to be involved in clinical research and academic work in chemotherapy-induced $\mathrm{FN}$ and in generating publications in this field. They were also required to be fluent English speakers.

\section{Literature review}

Ahead of the guidance group meeting, a literature review (details provided in Table 1) was performed to establish the current evidence base on the use of pegfilgrastim and identify key areas in which data and guidance are lacking or areas of inconsistency within these. This broad review was undertaken before development of the consensus statements. The search 
Table 1 Literature review exclusion criteria

\begin{tabular}{ll}
\hline Exclusion criteria & $\begin{array}{c}\text { Number } \\
\text { excluded }\end{array}$ \\
\hline $\begin{array}{l}\text { Published in } 1999 \text { or earlier } \\
\text { Studies in non-human animals/in vitro/ex vivo }\end{array}$ & 2 \\
Studies in children/adolescents & 12 \\
Does not include long-acting G-CSF & 89 \\
$\begin{array}{l}\text { Not receiving G-CSF for prophylaxis/treatment of chemotherapy-induced FN during cancer } \\
\text { treatment }\end{array}$ & 47 \\
$\begin{array}{l}\text { Not trial data, letter to editor, or case study } \\
\text { Does not contribute to research question: "In which circumstances is long-acting G-CSF } \\
\text { (pegfilgrastim) efficacious for prevention of chemotherapy-induced FN in individuals } \\
\text { diagnosed with cancer?" }\end{array}$ & 60 \\
Not phase II-IV RCTs, prospective non-randomized studies, letters to editor or case studies & 34 \\
Cannot be accessed & 1 \\
\hline $\begin{array}{l}\text { The final literature search was performed on 17 November 2015, ahead of the guidance group meeting. To capture } \\
\text { all phase II-IV trials with pegfilgrastim reference product, "1999" was selected as a cutoff for relevant publica- } \\
\text { tions; publications prior to this date would not be relevant }\end{array}$ \\
$F N$ febrile neutropenia, G-CSF granulocyte colony-stimulating factor, RCT randomized controlled trial
\end{tabular}

terms used for this literature search were ["neutropenia" AND "chemotherapy" AND ("long-acting G-CSF" OR pegfilgrastim OR peg-filgrastim OR "pegylated G-CSF" OR biosimilar OR Neulasta OR “LA EP 2006" OR Lonquex OR lipegfilgrastim OR ristempa OR neupeg OR pegasta OR neulastim OR coherus OR apotex OR apotes OR "mylan peg-filgrastim")] and ["neutropenia" AND "chemotherapy" AND "long-acting" AND "colony stimulating factor"].

A total of 446 unique references were identified from PubMed Central and the Cochrane database, providing data on the current use of pegfilgrastim. References were selected for review using the exclusion criteria detailed in Table 1. In all, 44 unique references were included in the final list and used to support development of the guidance recommendations in this publication.

\section{Development of guidance recommendations}

The guidance recommendations included in this publication are intended to fill the gaps identified in the current guidelines and were established based on findings from the literature review, as well as the experts' experience and opinions. An electronic survey and a subsequent consensus meeting were held to determine the wording and supporting content. Consensus was established using a Delphi-based method (Table 2), which is a well-established, structured, and systematic method of gaining consensus using a panel of experts [25].

The Delphi-based method was performed as follows:

1. First, the authors voted on their agreement with suggested consensus guidance statements via an anonymous electronic survey. Statements on which consensus was not reached were refined and adapted based on literature search findings and expert opinion.

2. The authors then discussed the updated statements at an interactive consensus meeting and refined the statements as required.

3. The authors voted anonymously on their agreement with the updated consensus guidance statements. If consensus could not be reached, there was further discussion on the relevant statement; the authors provided their rationale for agreement or disagreement with the proposed statement and it was refined further if necessary.

4. The authors then voted anonymously on their agreement with the final statement. If consensus was reached, the statement was included in this publication. If consensus was not reached, a recommendation was not made; however, relevant information relating to such statements is included where appropriate.

\section{Results}

\section{Guidance recommendations}

Consensus was reached on all guidance recommendations listed in this publication. The level (strength) of evidence for each recommendation was evaluated in line with widely used grading criteria [1]:

I. Evidence obtained from meta-analysis of multiple, welldesigned, controlled studies or from high-power randomized, controlled clinical trials 
Table 2 Delphi-based consensus criteria

\begin{tabular}{ll}
\hline Consensus reached & $\geq 75 \%$ vote "agree" or "strongly agree" \\
Group recommendation & $\geq 50 \%$ vote "agree" or "strongly agree" \\
Further evidence required & $<50 \%$ vote "agree" or "strongly agree" \\
\hline
\end{tabular}

Twelve advisors provided their response to the electronic survey and 11 participated and voted during the consensus meeting; one advisor did not respond to the survey but attended the consensus meeting; and two responded to the survey but did not attend the consensus meeting. All advisors are listed as authors on this paper. In the survey and meeting, consensus was reached if nine or more advisors voted "agree" or "strongly agree." Consensus was reached on three guidance recommendations through the electronic survey; the remaining statements were confirmed during the consensus meeting. A total of 19 proposed statements were discussed during this meeting. The structure of these discussions is detailed in the "Methods" section

II. Evidence obtained from at least one well-designed experimental study or low-power randomized, controlled clinical trial

III. Evidence obtained from well-designed, quasiexperimental studies such as non-randomized, controlled single-group, pre-post, cohort, time, or matched case-control studies

IV. Studies such as comparative and correlational descriptive and case studies

V. Evidence obtained from case reports and clinical examples

The European Organisation for Research and Treatment of Cancer guidelines were used as a source document for grading recommendations.

\section{General statements and recommendations}

Prevention of chemotherapy-associated FN is not yet optimal (consensus reached (83\%); evidence level II).

Prevention and treatment of chemotherapy-induced FN using G-CSF in clinical practice may often deviate from clinical guidelines [12, 26]. Furthermore, no clinical guidelines are available to support use of G-CSF in some situations, for example during the use of targeted cancer treatments. Studies suggest that the high-risk patients who require G-CSF treatment are often undertreated, with only $17 \%$ receiving appropriate G-CSF treatment [27].

When cure is the intention of chemotherapy, maintenance of planned dose intensity using G-CSF to prevent dose delays or dose reductions should be the standard of care (consensus reached (100\%); evidence level I).

In patients receiving chemotherapy or targeted treatments with curative intent, delays or dose reductions in chemotherapy can have a significant impact on the efficacy of treatment and can therefore impact patient survival [1, 4, 28]. It is our opinion that treatment delays due to avoidable circumstances such as FN should be prevented where possible. Routine use of short- or long-acting G-CSF is an established method for prophylaxis of FN $[1,2,8]$.

\section{Recommendations according to risk of FN}

In patients receiving chemotherapy and/or targeted agents with a FN risk $\geq 20 \%$, pegfilgrastim or short-acting G-CSF should be given from cycle 1 throughout all cycles of chemotherapy (consensus reached (100\%); evidence level I).

In patients receiving chemotherapy and/or targeted therapy with a FN risk 10-20\%, if factors that increase this risk (see Table 3) suggest that the overall risk of neutropeniarelated complications is $\geq 20 \%$, the patient should receive pegfilgrastim or short-acting G-CSF (consensus reached (100\%); evidence level V).

In patients receiving chemotherapy and/or targeted therapy even with a FN risk $<10 \%$, if special factors suggest that the overall risk of neutropenia-related complications is $\geq 20 \%$ (see Table 3), the patient should receive pegfilgrastim or shortacting G-CSF (consensus reached (100\%); evidence level V).

The decision to prescribe G-CSF should always be a joint decision between the patient and the treating physician. In patients with a treatment-associated FN risk of $<20 \%$, this group believes it is critical to consider other factors that may increase the risk of FN or result in poorer outcomes should it develop.

Patient-, disease-, and treatment-related factors should be considered and G-CSF should not be denied to a patient solely on the basis of treatment-related FN risk. Table 3 details factors that should be considered when assessing the risk of FN or associated negative outcomes. Once initiated, G-CSF should be continued through all cycles of chemotherapy [8].

Table 3 Factors possibly associated with elevating FN risk which should be considered when estimating the overall risk of FN [29]

Age $>65$ years

Low performance status (low Karnofsky index, high ECOG score)

Comorbidities, including COPD, heart failure (NYHA III-IV), HIV

infection, autoimmune disease, marked renal impairment

Significantly advanced, symptomatic tumor disease

Prior chemotherapy

Laboratory parameters, including anemia, lymphocytopenia $(<700$ cells/ $\mu$ l), hyperalbuminuria, hyperbilirubinemia

This table is based on the German G-CSF guidelines group consensus statement [29]. All factors listed in this table are likely to increase the risk of FN, particularly when present in combination. Many other comorbidities have been linked with a possible increase in the risk of FN, but their associated risks have not been definitively proven. These factors should be considered when estimating the overall risk of FN

$C O P D$ chronic obstructive pulmonary disease, ECOG Eastern Cooperative Oncology Group, $F N$ febrile neutropenia, G-CSF granulocyte colony-stimulating factor, $H I V$ human immunodeficiency virus, NYHA New York Heart Association 
More specific recommendations for patients with hematologic malignancies are listed later in this publication.

\section{Use of pegfilgrastim vs short-acting G-CSF}

Clinical trial data suggest a similar efficacy and safety profile with pegfilgrastim and 11 days' filgrastim. ${ }^{1}$ If 11 days' filgrastim is not utilized, pegfilgrastim should be given in preference to a reduced duration of daily filgrastim (consensus reached (91\%); evidence level I).

A similar efficacy and safety profile has been seen in individual studies comparing an average of 11 days' filgrastim treatment with pegfilgrastim [30-35], and meta-analyses suggest that, overall, pegfilgrastim may be more efficacious than filgrastim [37, 38] (Fig. 1). Across studies, the efficacy benefits demonstrated include a reduction in incidence of $\mathrm{FN}$, a reduction in FN-related hospitalizations, and improved time to ANC recovery with pegfilgrastim vs filgrastim [37-39]. These findings are also supported by data from clinical practice [40-43].

In clinical practice, duration of filgrastim treatment is routinely shorter than 11 days and often shorter than 7 days [40, $41,43-45]$. It is not clear whether a reduced duration of filgrastim could achieve similar efficacy and safety benefits to pegfilgrastim or 11 days' filgrastim. Furthermore, these data suggest a reduced duration of filgrastim may be associated with worse outcomes compared with 11 days' filgrastim or pegfilgrastim $[13,36,46]$. As such, it is our opinion that pegfilgrastim may be preferable to filgrastim in clinical practice, particularly if there is a risk that filgrastim will not be continued for at least 11 days. If filgrastim is used, it should be maintained until the neutropenia has passed and neutrophil count has returned to normal, which may take up to 14 days $[47,48]$.

Based on the convenience and patient adherence, pegfilgrastim may be preferred to 11 days' filgrastim for prevention of chemotherapy-induced FN. This is particularly the case in frail or elderly patients (consensus reached (100\%); evidence level V).

In clinical practice, patients rarely receive the full dose of filgrastim, partially due to limitations with perceived patient adherence and convenience [13, 36, 42, 49, 50]. While daily administration of filgrastim is required, pegfilgrastim (reference product and biosimilar) is a single once-per-cycle injection [14]. Once-per-cycle dosing may be more convenient for patients, as there is no requirement for daily self-administration, hospital visits, or regular tests to evaluate ANC levels. It was suggested by the group that this may be associated with increased treatment adherence from patients, thus favoring the use of pegfilgrastim over filgrastim; however, this has not

\footnotetext{
${ }^{1}$ Average duration of filgrastim treatment was 11 days in clinical trials of filgrastim vs pegfilgrastim [30-36].
}

been thoroughly investigated in randomized controlled studies.

\section{Use of pegfilgrastim vs short-acting G-CSF_-additional topics of interest}

This group could reach no clear consensus on whether pegfilgrastim or filgrastim is more appropriate for patients who experience bone pain. In patients who experience bone pain or other G-CSF-related side effects, consider switching from filgrastim to pegfilgrastim or vice versa. Based on very limited data, it may also be possible to reduce the dose of pegfilgrastim treatment [51]; although, this represents offlabel use and the effectiveness of this approach is disputed. As such, reducing the dose of pegfilgrastim is not recommended.

No clear consensus was reached on the optimal use of pegfilgrastim in patients with renal impairment. The opinion of this group is that no dose reduction is required in these patients, as pegfilgrastim is neutrophil-eliminated rather than renally eliminated, and studies suggest renal dysfunction has no effect on the pharmacokinetics of this agent [14].

\section{Recommendations according to treatment type}

In the absence of evidence from clinical trials, pegfilgrastim is not appropriate in patients receiving weekly chemotherapy (consensus reached (100\%); evidence level V).

Weekly chemotherapy regimens are becoming increasingly common, particularly with agents including taxanes, gemcitabine, and vinorelbine; however, data on the use of pegfilgrastim with weekly chemotherapy regimens are limited. One prospective, non-randomized study $(n=24)$ has demonstrated positive outcomes with pegfilgrastim administered on a fortnightly schedule, on the same day as chemotherapy, in patients receiving weekly chemotherapy [52], suggesting its use may be possible in these patients. At the current time, however, our opinion is that short-acting G-CSF may be more appropriate until further evidence is available.

Pegfilgrastim has been used effectively in patients receiving fortnightly chemotherapy regimens (R-CHOP-14); in this instance, the other recommendations detailed in this publication apply [53].

In patients receiving split-dose chemotherapy, pegfilgrastim administration is recommended $24 \mathrm{~h}$ after the last chemotherapy dose (consensus reached (100\%); evidence level II).

In split-dose regimens, chemotherapy treatment may be administered on multiple days throughout one chemotherapy cycle. Administration of pegfilgrastim is recommended $\geq 24 \mathrm{~h}$ after the last chemotherapy dose and $\geq 14$ days before the next dose. Two studies have demonstrated positive outcomes with this approach, though data are limited [54, 55]. In clinical practice, this is considered a well-established and appropriate 
Fig. 1 Incidence of FN in Clinical Trials. Superscript a: FN all cycles. Superscript $b$ : FN $\geq 1$ cycle. Superscript c: FN cycles 1 and 2. $C I$ confidence interval, $F N$ febrile neutropenia, $R R$ risk ratio $[30-34,38]$

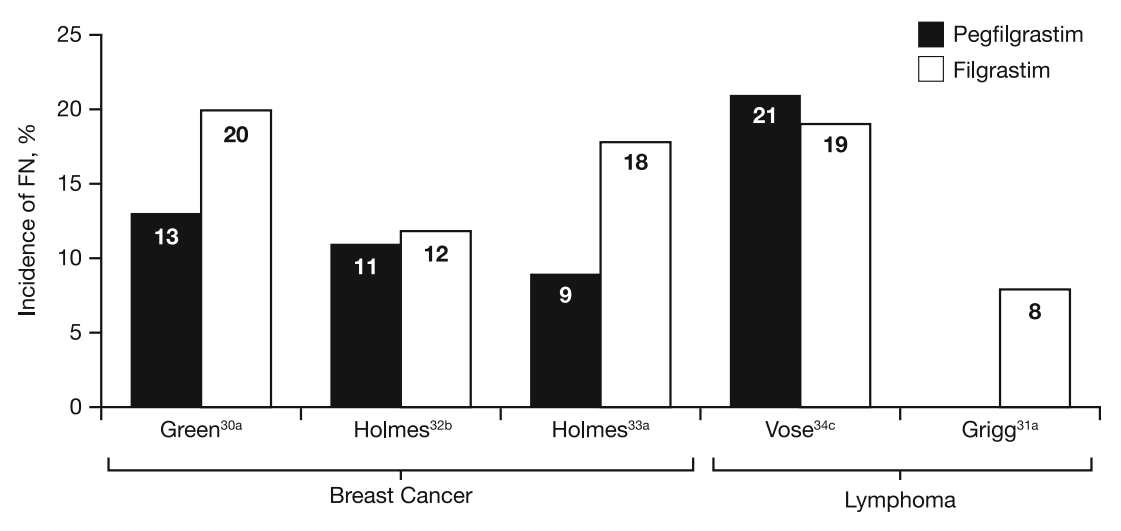

Pooled RR (95\% Cl) for FN* (pegfilgrastim vs filgrastim): $0.64(0.43-0.97) ; P=0.033^{38}$ approach for use of pegfilgrastim in patients receiving splitdose chemotherapy.

If a need for G-CSF has been identified for maintenance of treatment dose or prevention of chemotherapy-induced FN in patients receiving palliative treatment, the issues of convenience and adherence may favor use of pegfilgrastim. Dose reductions or change in chemotherapy regimen should also be considered (consensus reached (100\%); evidence level V).

Although treatment delays and dose reductions may be less concerning in patients receiving palliative treatment, G-CSF may be required in high-risk patients to avoid the serious and even life-threatening complications associated with FN. Furthermore, maintenance of dose intensity can be associated with significant survival benefits in patients receiving palliative treatment [56, 57].

In patients receiving palliative care requiring G-CSF treatment, guidance recommendations discussed in this publication apply. When possible, switching to an alternate treatment, reducing treatment dose, or providing larger breaks between treatment cycles may be considered in preference, or in addition, to use of G-CSF.

Once initiated, pegfilgrastim prophylaxis should be continued throughout all cycles of chemotherapy (consensus reached (100\%); evidence level II).

When pegfilgrastim prophylaxis is discontinued, the risk of FN increases in the subsequent chemotherapy cycle; if pegfilgrastim is continued throughout treatment, a consistently low risk of FN is maintained [58]. This group suggests that the perceived convenience and patient adherence benefits associated with pegfilgrastim vs filgrastim may favor consistent use throughout treatment.

In this new era of targeted and immunotherapies, additional trials with G-CSF are required (consensus reached (100\%); evidence level V).

There are limited data on the use of G-CSF for prevention of FN induced by targeted agents and immunotherapies. Targeted agents with various mechanisms of action, including immunomodulatory agents (e.g., lenalidomide, pomalidomide), proteasome inhibitors (e.g., bortezomib, carfilzomib), monoclonal antibodies (e.g., obinutuzumab, brentuximab vedotin), and B cell receptor inhibitors (e.g., ibrutinib, idelalisib), may be associated with neutropenia, though the incidence of $\mathrm{FN}$ is variable [59-64]. In the absence of specific guidance on use of G-CSF with these agents, the guidance recommendations for chemotherapy in this publication should be applied.

\section{Special considerations for patients with hematologic malignancies}

In patients with multiple myeloma (MM) needing G-CSF, pegfilgrastim can be given in some instances, but filgrastim may have more applications given some current regimens and can be given concurrently with some treatment regimens (e.g., immunomodulatory drugs and proteasome inhibitors) (consensus reached (100\%); evidence level V).

There are limited studies with pegfilgrastim in patients with MM. Many patients are $\geq 65$ years old with a high risk of $F N$ and therefore require G-CSF treatment, although risk of FN is regimen dependent. MM guidelines recommend use of a G-CSF to allow optimal duration of active therapy; this should be initiated if grade 4 neutropenia (uncomplicated) or grade 3 neutropenia (with infection) occurs and continued until disease progression or toxicity is encountered $[65,66]$. Primary G-CSF prophylaxis is recommended when the rate of grade 3 or 4 neutropenia is expected to be $>50 \%$ and with low or intermediate risk regimens when tumor- or patient-related risk factors are present and ANC is $<1000$ cells $/ \mathrm{mL}$ at the start of chemotherapy [66].

Weekly and fortnightly chemotherapy regimens are more frequent in treatment of MM, which may result in a greater role for filgrastim than pegfilgrastim. Risk of FN is less clear with non-chemotherapy regimens; the most appropriate choice of G-CSF with some agents (e.g., immunomodulatory drugs and proteasome inhibitors) has not yet been determined.

In newly diagnosed patients with acute myeloid leukemia (AML) receiving induction therapy, filgrastim could be considered. In patients receiving consolidation chemotherapy with curative intent, pegfilgrastim may be preferred to filgrastim (consensus reached (100\%); evidence level II). 
There are limited studies with pegfilgrastim in patients with AML and its long-term effects have not been established. Although data are emerging, there is currently no strong evidence to support its use in this patient population [14, 67-70].

Pegfilgrastim cannot be recommended during induction therapy and is contraindicated in patients with chronic myeloid leukemia [14].

In patients with lymphoma/chronic lymphocytic leukemia, or MM receiving targeted treatments, pegfilgrastim or shortacting G-CSF can be considered if needed to continue treatment (consensus reached (100\%); evidence level IV).

There are limited data on the use of G-CSF for prevention of FN induced by targeted agents and immunotherapies, although many targeted agents have an associated FN risk (please refer to earlier recommendations). G-CSF support should be considered if grade $\geq 3$ neutropenia occurs, and its use is recommended in the Summary of Product Characteristics for some targeted agents $[59,60]$.

\section{Additional topics of interest}

Lipegfilgrastim, a long-acting filgrastim approved by the EMA, has been shown to have a similar efficacy and safety profile vs pegfilgrastim for prophylaxis of chemotherapyassociated FN. Two pivotal studies, and one dose-finding study, provided direct evidence for the effectiveness of lipegfilgrastim prophylaxis vs pegfilgrastim prophylaxis [15, 71-73].

Lipegfilgrastim is primarily available in Europe but has limited availability worldwide compared with pegfilgrastim. It should be noted that no specific recommendations have been made on the most appropriate use of lipegfilgrastim in this publication, as lipegfilgrastim data were not considered during the guidance group meeting and as such did not influence the guidance recommendations agreed.

\section{Discussion}

FN is a serious side effect of many cancer treatments and can lead to severe infection and sepsis with potentially fatal consequences [1]. G-CSF, including pegfilgrastim, are recommended for primary and secondary prophylaxis of chemotherapy-induced FN and have demonstrated efficacy in clinical trials and daily practice $[1,2,9]$. Pegfilgrastim is the only long-acting G-CSF available worldwide and is associated with the most clinical data and experience. The guidance statements are not absolute recommendations but are intended as a guide for the clinician in daily clinical practice; they should be used alongside current guidelines. The expert panel suggests that the guidance statements in this publication should be used in parallel with existing guidelines to optimize the appropriate use of G-CSF and of pegfilgrastim in cancer patients in clinical practice.
Acknowledgments Editorial assistance was provided by Ogilvy 4D, Oxford, UK and funded by Hexal AG. The authors would like to acknowledge Dr. A. Krendyukov (Global Medical Affairs, Hexal AG) for valuable scientific support in preparation of the expert meeting and discussions.

Sandoz GmbH funded the Consensus Advisory Board. No funding was provided for the development of this paper.

\section{Compliance with ethical standards}

Conflict of interest Dr. Aapro received honoraria and/or consultant fees from Amgen, Bayer, BMS, Celgene, Cephalon, Chugai, Clinigen, Eisai, GenomicHealth, GSK, Helsinn, Hospira, Ipsen, J\&J, Kyowa, Merck, Novartis, OrthoBiotech, Pfizer, PierreFabre, Roche, Sandoz, Sanofi, Tesaro, Taiho, Teva, and Vifor. Dr. Boccia consulted for Sandoz $\mathrm{GmbH}$. Professor Leonard consulted for Sandoz GmbH. Professor Camps has nothing to disclose. Professor Campone has nothing to disclose. Professor Choquet consulted for Sandoz GmbH. Professor Danova consulted for Sandoz GmbH. Dr. Glaspy consulted for Sandoz GmbH. Professor Hus received speaker's fees, travel grants, and/or acted on advisory boards for Amgen, Celgene, Janssen, Roche, and Sandoz GmbH. Professor Link received research funding and honoraria, acted on speakers' bureau, and/or consulted for Amgen, Celgene, Chugai, Lilly, MSD Oncology, Mundipharma, Novartis, Pfizer, Hexal-Sandoz, Teva, and Vifor Pharma. Professor Sliwa consulted for Sandoz GmbH. Professor Tesch received honoraria and/or consultant fees from Amgen, Sandoz GmBH, Novartis, and Teva. Dr. Valero consulted for Amgen, Sandoz GmbH, and Roche.

Open Access This article is distributed under the terms of the Creative Commons Attribution-NonCommercial 4.0 International License (http:// creativecommons.org/licenses/by-nc/4.0/), which permits any noncommercial use, distribution, and reproduction in any medium, provided you give appropriate credit to the original author(s) and the source, provide a link to the Creative Commons license, and indicate if changes were made.

\section{References}

1. Aapro MS, Bohlius J, Cameron DA, Dal Lago L, Donnelly JP, Kearney N, Lyman GH, Pettengell R, Tjan-Heijnen VC, Walewski J, Weber DC, Zielinski C (2011) 2010 update of EORTC guidelines for the use of granulocyte-colony stimulating factor to reduce the incidence of chemotherapy-induced febrile neutropenia in adult patients with lymphoproliferative disorders and solid tumours. Eur J Cancer 47(1):8-32. doi:10.1016/j.ejca.2010. 10.013

2. Klastersky J, de Naurois J, Rolston K, Rapoport B, Maschmeyer G, Aapro M, Herrstedt J, Committee EG (2016) Management of febrile neutropaenia: ESMO Clinical Practice Guidelines. Ann Oncol 27(suppl 5):v111-v118. doi:10.1093/annonc/mdw325

3. Freifeld AG, Bow EJ, Sepkowitz KA, Boeckh MJ, Ito JI, Mullen CA, Raad RKV II, Young JA, Wingard JR, Infectious Diseases Society of A (2011) Clinical practice guideline for the use of antimicrobial agents in neutropenic patients with cancer: 2010 update by the Infectious Diseases Society of America. Clin Infect Dis 52(4):427-431. doi:10.1093/cid/ciq147

4. Wang L, Baser O, Kutikova L, Page JH, Barron R (2015) The impact of primary prophylaxis with granulocyte colonystimulating factors on febrile neutropenia during chemotherapy: a systematic review and meta-analysis of randomized controlled trials. Support Care Cancer. doi:10.1007/s00520-015-2686-9 
5. Caggiano V, Weiss RV, Rickert TS, Linde-Zwirble WT (2005) Incidence, cost, and mortality of neutropenia hospitalization associated with chemotherapy. Cancer 103(9):1916-1924. doi:10.1002/ cncr.20983

6. Truong J, Lee EK, Trudeau ME, Chan KK (2015) Interpreting febrile neutropenia rates from randomized controlled trials for consideration of primary prophylaxis in the real world: a systematic review and meta-analysis. Ann Oncol 27(4):608-618. doi:10.1093/ annonc/mdv619

7. Crawford J, Dale DC, Kuderer NM, Culakova E, Poniewierski MS, Wolff D, Lyman GH (2008) Risk and timing of neutropenic events in adult cancer patients receiving chemotherapy: the results of a prospective nationwide study of oncology practice. J Natl Compr Cancer Netw 6(2):109-118

8. Smith TJ, Bohlke K, Armitage JO (2015) Recommendations for the use of white blood cell growth factors: American Society of Clinical Oncology Clinical Practice Guideline Update. J Oncol Pract 11(6): 511-513. doi:10.1200/JOP.2015.006742

9. Leonard RC, Mansi JL, Keerie C, Yellowlees A, Crawford S, Benstead K, Matthew R, Adamson D, Chan S, Grieve R, AngloCeltic Collaborative Oncology G (2015) A randomised trial of secondary prophylaxis using granulocyte colony-stimulating factor ('SPROG' trial) for maintaining dose intensity of standard adjuvant chemotherapy for breast cancer by the Anglo-Celtic Cooperative Group and NCRN. Ann Oncol 26(12):2437-2441. doi:10.1093/ annonc/mdv389

10. Kelly S, Wheatley D (2009) Prevention of febrile neutropenia: use of granulocyte colony-stimulating factors. Br J Cancer 101(Suppl 1):S6-10. doi:10.1038/sj.bjc.6605269

11. Barnes G, Pathak A, Schwartzberg L (2014) G-CSF utilization rate and prescribing patterns in United States: associations between physician and patient factors and GCSF use. Cancer Med 3(6):14771484. doi:10.1002/cam4.344

12. Link H, Nietsch J, Kerkmann M, Ortner P, Supportive Care Group of the German Cancer S (2016) Adherence to granulocyte-colony stimulating factor (G-CSF) guidelines to reduce the incidence of febrile neutropenia after chemotherapy-a representative sample survey in Germany. Support Care Cancer 24(1):367-376. doi:10.1007/ s00520-015-2779-5

13. Weycker D, Hackett J, Edelsberg JS, Oster G, Glass AG (2006) Are shorter courses of filgrastim prophylaxis associated with increased risk of hospitalization? Ann Pharmacother 40(3):402-407. doi:10. 1345/aph.1G516

14. Amgen Ltd (2015) Neulasta ${ }^{\circledR}$ summary of product characteristics. http://www.ema.europa.eu/docs/en GB/document library/EPAR Product_Information/human/000420/WC500025945.pdf. Accessed 1 March 2017

15. Teva Pharma B.V. (2015) Lonquex ${ }^{\circledR}$ summary of product characteristics. http://www.ema.europa.eu/docs/en GB/document library/EPAR - Product Information/human/002556/ WC500148380.pdf. Accessed 30 March 2017

16. Vogel CL, Wojtukiewicz MZ, Carroll RR, Tjulandin SA, BarajasFigueroa LJ, Wiens BL, Neumann TA, Schwartzberg LS (2005) First and subsequent cycle use of pegfilgrastim prevents febrile neutropenia in patients with breast cancer: a multicenter, doubleblind, placebo-controlled phase III study. J Clin Oncol 23(6):11781184. doi:10.1200/jco.2005.09.102

17. Mey UJ, Maier A, Schmidt-Wolf IG, Ziske C, Forstbauer H, Banat GA, Reber M, Strehl JW, Gorschlueter M (2007) Pegfilgrastim as hematopoietic support for dose-dense chemoimmunotherapy with R-CHOP-14 as first-line therapy in elderly patients with diffuse large B cell lymphoma. Support Care Cancer 15(7):877-884. doi: 10.1007/s00520-006-0201-Z

18. Montella L, Addeo R, Guarrasi R, Cennamo G, Faiola V, Capasso E, Caraglia M, Del Prete S (2010) Once-per-cycle pegfilgrastim in breast cancer patients treated with docetaxel/epidoxorubicin/ cyclophosphamide. Eur J Cancer Care (Engl) 19(2):200-204. doi: 10.1111/j.1365-2354.2008.01004.x

19. Ozer H, Mirtsching B, Rader M, Luedke S, Noga SJ, Ding B, Dreiling L (2007) Neutropenic events in community practices reduced by first and subsequent cycle pegfilgrastim use. Oncologist 12(4):484 494. doi:10.1634/theoncologist.12-4-484

20. Pro B, Fayad L, McLaughlin P, Romaguera J, Hagemeister FB, Rodriguez MA, Goy A, Loyer E, Younes A (2006) Pegfilgrastim administered in a single fixed dose is effective in inducing neutrophil count recovery after paclitaxel and topotecan chemotherapy in patients with relapsed aggressive non-Hodgkin's lymphoma. Leuk Lymphoma 47(3):481-485. doi:10.1080/10428190500305802

21. European Commission (2013) Consensus information paper: what you need to know about biosimilar medicinal products. http://www. medicinesforeurope.com/wp-content/uploads/2016/03/ biosimilars report en.pdf. Accessed 30 March 2017

22. Gascon P, Tesch $\bar{H}$, Verpoort K, Rosati MS, Salesi N, Agrawal S, Wilking N, Barker H, Muenzberg M, Turner M (2013) Clinical experience with Zarzio ${ }^{\circledR}$ in Europe: what have we learned? Support Care Cancer 21(10):2925-2932. doi:10.1007/s00520013-1911-7

23. Welte K (2014) G-CSF: filgrastim, lenograstim and biosimilars. Expert Opin Biol Ther 14(7):983-993. doi:10.1517/14712598. 2014.905537

24. Aapro M (2013) Biosimilars in oncology: current and future perspectives. Generics and Biosimilars Initiative Journal 2(2):91-93

25. Hsu CS, Sandford BA (2007) The Delphi technique: making sense of consensus. Pract Assess Res Eval 12(10):1-8

26. Wright JD, Neugut AI, Ananth CV, Lewin SN, Wilde ET, Lu YS, Herzog TJ, Hershman DL (2013) Deviations from guideline-based therapy for febrile neutropenia in cancer patients and their effect on outcomes. JAMA Intern Med 173(7):559-568. doi:10.1001/ jamainternmed.2013.2921

27. Potosky AL, Malin JL, Kim B, Chrischilles EA, Makgoeng SB, Howlader N, Weeks JC (2011) Use of colony-stimulating factors with chemotherapy: opportunities for cost savings and improved outcomes. J Natl Cancer Inst 103(12):979-982. doi:10.1093/jnci/ djr 152

28. Lyman GH (2006) Chemotherapy dose intensity and quality cancer care. Oncology (Williston Park) 20(14 Suppl 9):16-25

29. German Guideline Program in Oncology (2016) S3-Leitlinie Supportive Therapie bei onkologischen PatientInnen. Leitlinienprogramm Onkologie. http://leitlinienprogramm-onkologie.de/SupportiveTherapie.95.0.html. Accessed 27 March 2017

30. Green MD, Koelbl H, Baselga J, Galid A, Guillem V, Gascon P, Siena S, Lalisang RI, Samonigg H, Clemens MR, Zani V, Liang BC, Renwick J, Piccart MJ (2003) A randomized double-blind multicenter phase III study of fixed-dose single-administration pegfilgrastim versus daily filgrastim in patients receiving myelosuppressive chemotherapy. Ann Oncol 14(1):29-35

31. Grigg A, Solal-Celigny P, Hoskin P, Taylor K, McMillan A, Forstpointner R, Bacon P, Renwick J, Hiddemann W (2003) Open-label, randomized study of pegfilgrastim vs. daily filgrastim as an adjunct to chemotherapy in elderly patients with nonHodgkin's lymphoma. Leuk Lymphoma 44(9):1503-1508. doi: 10.1080/1042819031000103953

32. Holmes FA, Jones SE, O'Shaughnessy J, Vukelja S, George T, Savin M, Richards D, Glaspy J, Meza L, Cohen G, Dhami M, Budman DR, Hackett J, Brassard M, Yang BB, Liang BC (2002) Comparable efficacy and safety profiles of once-per-cycle pegfilgrastim and daily injection filgrastim in chemotherapyinduced neutropenia: a multicenter dose-finding study in women with breast cancer. Ann Oncol 13(6):903-909

33. Holmes FA, O'Shaughnessy JA, Vukelja S, Jones SE, Shogan J, Savin M, Glaspy J, Moore M, Meza L, Wiznitzer I, Neumann TA, Hill LR, Liang BC (2002) Blinded, randomized, multicenter 
study to evaluate single administration pegfilgrastim once per cycle versus daily filgrastim as an adjunct to chemotherapy in patients with high-risk stage II or stage III/IV breast cancer. J Clin Oncol 20(3):727-731

34. Vose JM, Crump M, Lazarus H, Emmanouilides C, Schenkein D, Moore J, Frankel S, Flinn I, Lovelace W, Hackett J, Liang BC (2003) Randomized, multicenter, open-label study of pegfilgrastim compared with daily filgrastim after chemotherapy for lymphoma. $\mathrm{J}$ Clin Oncol 21(3):514-519

35. Zhang W, Jiang Z, Wang L, Li C, Xia J (2015) An open-label, randomized, multicenter dose-finding study of once-per-cycle pegfilgrastim versus daily filgrastim in Chinese breast cancer patients receiving TAC chemotherapy. Med Oncol 32(5):147. doi:10. 1007/s12032-015-0537-7

36. Mucenski JW, Shogan JE (2003) Maximizing the outcomes in cancer patients receiving chemotherapy through optimal use of colonystimulating factor. J Manag Care Pharm 9(2 Suppl):10-14

37. Cooper KL, Madan J, Whyte S, Stevenson MD, Akehurst RL (2011) Granulocyte colony-stimulating factors for febrile neutropenia prophylaxis following chemotherapy: systematic review and meta-analysis. BMC Cancer 11:404. doi:10.1186/1471-2407-11404

38. Pinto L, Liu Z, Doan Q, Bernal M, Dubois R, Lyman G (2007) Comparison of pegfilgrastim with filgrastim on febrile neutropenia, grade IV neutropenia and bone pain: a meta-analysis of randomized controlled trials. Curr Med Res Opin 23(9):2283-2295. doi:10. 1185/030079907x219599

39. Kuderer NM, Khorana AA, Lyman GH, Francis CW (2007) A meta-analysis and systematic review of the efficacy and safety of anticoagulants as cancer treatment: impact on survival and bleeding complications. Cancer 110(5):1149-1161. doi:10.1002/cncr.22892

40. Almenar Cubells D, Bosch Roig C, Jimenez Orozco E, Alvarez R, Cuervo JM, Diaz Fernandez N, Sanchez Heras AB, Galan Brotons A, Giner Marco V, Codes MDVM (2013) Effectiveness of daily versus non-daily granulocyte colony-stimulating factors in patients with solid tumours undergoing chemotherapy: a multivariate analysis of data from current practice. Eur J Cancer Care (Engl) 22(3): 400-412. doi:10.1111/ecc.12043

41. Almenar D, Mayans J, Juan O, Bueno JM, Lopez JI, Frau A, Guinot M, Cerezuela P, Buscalla EG, Gasquet JA, Sanchez J (2009) Pegfilgrastim and daily granulocyte colony-stimulating factor: patterns of use and neutropenia-related outcomes in cancer patients in Spain - results of the LEARN Study. Eur J Cancer Care (Engl) 18(3):280-286. doi:10.1111/j.1365-2354.2008.00959.x

42. Gascon P, Aapro M, Ludwig H, Bokemeyer C, Boccadoro M, Turner M, Denhaerynck K, MacDonald K, Abraham I (2015) Treatment patterns and outcomes in the prophylaxis of chemotherapy-induced (febrile) neutropenia with biosimilar filgrastim (the MONITOR-GCSF study). Support Care Cancer. doi:10.1007/s00520-015-2861-z

43. Naeim A, Henk HJ, Becker L, Chia V, Badre S, Li X, Deeter R (2013) Pegfilgrastim prophylaxis is associated with a lower risk of hospitalization of cancer patients than filgrastim prophylaxis: a retrospective United States claims analysis of granulocyte colonystimulating factors (G-CSF). BMC Cancer 13:11. doi:10.1186/ 1471-2407-13-11

44. Weycker D, Malin J, Kim J, Barron R, Edelsberg J, Kartashov A, Oster G (2009) Risk of hospitalization for neutropenic complications of chemotherapy in patients with primary solid tumors receiving pegfilgrastim or filgrastim prophylaxis: a retrospective cohort study. Clin Ther 31(5):1069-1081. doi:10.1016/j.clinthera.2009. 05.019

45. Falandry C, Campone M, Cartron G, Guerin D, Freyer G (2010) Trends in G-CSF use in 990 patients after EORTC and ASCO guidelines. Eur J Cancer 46(13):2389-2398. doi:10.1016/j.ejca. 2010.04.031
46. Weycker D, Li X, Edelsberg J, Barron R, Kartashov A, Xu H, Lyman GH (2014) Risk and consequences of chemotherapyinduced febrile neutropenia in patients with metastatic solid tumors. J Oncol Pract. doi:10.1200/JOP.2014.001492

47. Amgen Ltd (2015) Neupogen ${ }^{\circledR}$ summary of product characteristics. http://www.ema.europa.eu/docs/en_GB/document_library/EPAR_Product Information/human/000917/WC500046525.pdf. Āccessed 27 March 2017

48. Sandoz (2015) Filgrastim HEXAL ${ }^{\circledR}$ summary of product characteristics. http://www.ema.europa.eu/docs/en GB/document library/ EPAR - Product Information/human/0007̄26/WC500028282.pdf. Accessed 30 March 2017

49. Morrison VA, Wong M, Hershman D, Campos LT, Ding B, Malin J (2007) Observational study of the prevalence of febrile neutropenia in patients who received filgrastim or pegfilgrastim associated with 3-4 week chemotherapy regimens in community oncology practices. J Manag Care Pharm 13(4):337-348

50. von Minckwitz G, Kummel S, du Bois A, Eiermann W, Eidtmann H, Gerber B, Hilfrich J, Huober J, Costa SD, Jackisch C, Grasshoff ST, Vescia S, Skacel T, Loibl S, Mehta KM, Kaufmann M (2008) Pegfilgrastim $+/$ - ciprofloxacin for primary prophylaxis with TAC (docetaxel/doxorubicin/cyclophosphamide) chemotherapy for breast cancer. Results from the GEPARTRIO study. Ann Oncol 19(2):292-298. doi:10.1093/annonc/mdm438

51. Kim E, Jin R, Choi K, Frankel PH, Somlo G (2010) Safety and efficacy of low-dose pegfilgrastim (pegfil) in maintaining chemotherapy (CT) dose density in patients (pts) receiving docetaxel/ doxorubicin/cyclophosphamide (TAC) or doxorubicin/ cyclophosphamide (AC) as neoadjuvant chemotherapy (NCT) for stage II-III breast cancer (BC). J Clin Oncol 28(suppl.):Abstract e19561

52. Lokich J (2005) Same-day pegfilgrastim and chemotherapy. Cancer Investig 23(7):573-576. doi:10.1080/07357900500276899

53. Zeynalova S, Ziepert M, Scholz M, Schirm S, Zwick C, Pfreundschuh M, Loeffler M, German High-Grade Non-Hodgkin Lymphoma Study G (2013) Comparison and modelling of pegylated or unpegylated G-CSF schedules in CHOP-14 regimen of elderly patients with aggressive B-cell lymphoma. Ann Hematol 92(12):1641-1652. doi:10.1007/s00277-013-1842-x

54. Mattioli R, Gridelli C, Castellanos J, Duque A, Falcone A, Mansutti M, Bacon P, Lawrinson S, Skacel T, Casas A (2009) Use of pegfilgrastim support on day 9 to maintain relative dose intensity of chemotherapy in breast cancer patients receiving a day 1 and 8 CMF regimen. Clin Transl Oncol 11(12):842-848

55. Riedel RF, Andrews C, Garst J, Dunphy F, Herndon JE 2nd, Blackwell S, Barbour S, Crawford J (2007) A phase II trial of carboplatin/vinorelbine with pegfilgrastim support for the treatment of patients with advanced non-small cell lung cancer. J Thorac Oncol 2(6):520-525. doi:10.1097/JTO.0b013e318060107c

56. Prasad N, Bakshi A, Deshmukh C, Hingmire S, Ranade A, Parikh P (2012) Importance of dose intensity in treatment of advanced nonsmall cell lung cancer in the elderly. South Asian J Cancer 1(1):915. doi:10.4103/2278-330X.96494

57. Gennari A, D'Amico M, Corradengo D (2011) Extending the duration of first-line chemotherapy in metastatic breast cancer: a perspective review. Ther Adv Med Oncol 3(5):229-232. doi:10.1177/ 1758834011413423

58. Aarts MJ, Peters FP, Mandigers CM, Dercksen MW, Stouthard JM, Nortier HJ, van Laarhoven HW, van Warmerdam LJ, van de Wouw AJ, Jacobs EM, Mattijssen V, van der Rijt CC, Smilde TJ, van der Velden AW, Temizkan M, Batman E, Muller EW, van Gastel SM, Borm GF, Tjan-Heijnen VC (2013) Primary granulocyte colonystimulating factor prophylaxis during the first two cycles only or throughout all chemotherapy cycles in patients with breast cancer at risk for febrile neutropenia. J Clin Oncol 31(34):4290-4296. doi: 10.1200/jco.2012.44.6229 
59. Roche Products Ltd (2015) Gazyvaro ${ }^{\circledR}$ summary of product characteristics. http:/www.ema.europa.eu/docs/en_GB/document library/ EPAR - Product_Information/human/002799/WC5001715 594 .pdf. Accessed 30 March 2017

60. Takeda Ltd (2016) Adcetris ${ }^{\circledR}$ summary of product characteristics. http://www.ema.europa.eu/docs/en_GB/document_library/EPAR _Product_Information/human/002455/WC500135055.pdf. Accessed 30 March 2017

61. Celgene Ltd (2015) Revlimid ${ }^{\circledR}$ summary of product characteristics. http://www.ema.europa.eu/docs/en_GB/document_library/EPAR__Product_Information/human/000717/WC5000056018.pdf. Accessed 30 March 2017

62. Janssen-Cilag Ltd (2015) Velcade ${ }^{\circledR}$ summary of product characteristics. http://www.ema.europa.eu/docs/en_GB/document_library/ EPAR__Product_Information/human/000539/WC500048471. pdf. Accessed 30 March 2017

63. Janssen-Cilag Ltd (2015) Imbruvica ${ }^{\circledR}$ summary of product characteristics. http://www.ema.europa.eu/docs/en_GB/document library/EPAR_-_Product_Information/human/003791/ WC500177775.pdf. Accessed 30 March 2017

64. Gilead Sciences Ltd (2015) Zydelig ${ }^{\circledR}$ summary of product characteristics. http://www.ema.europa.eu/docs/en_GB/document library/EPAR__Product Information/human/003843/ WC500175377.pdf. Accessed 30 March 2017

65. Terpos E, Kleber M, Engelhardt M, Zweegman S, Gay F, Kastritis E, van de Donk NW, Bruno B, Sezer O, Broijl A, Bringhen S, Beksac M, Larocca A, Hajek R, Musto P, Johnsen HE, Morabito F, Ludwig H, Cavo M, Einsele H, Sonneveld P, Dimopoulos MA, Palumbo A, European Myeloma N (2015) European Myeloma Network guidelines for the management of multiple myelomarelated complications. Haematologica 100(10):1254-1266. doi:10. 3324/haematol.2014.117176

66. Palumbo A, Blade J, Boccadoro M, Palladino C, Davies F, Dimopoulos M, Dmoszynska A, Einsele H, Moreau P, Sezer O, Spencer A, Sonneveld P, San Miguel J (2012) How to manage neutropenia in multiple myeloma. Clin Lymphoma Myeloma Leuk 12(1):5-11. doi:10.1016/j.clml.2011.11.001
67. Braess J, Spiekermann K, Staib P, Gruneisen A, Wormann B, Ludwig WD, Serve H, Reichle A, Peceny R, Oruzio D, Schmid C, Schiel X, Hentrich M, Sauerland C, Unterhalt M, Fiegl M, Kern W, Buske C, Bohlander S, Heinecke A, Baurmann H, Beelen DW, Berdel WE, Buchner T, Hiddemann W (2009) Dose-dense induction with sequential high-dose cytarabine and mitoxantone (SHAM) and pegfilgrastim results in a high efficacy and a short duration of critical neutropenia in de novo acute myeloid leukemia: a pilot study of the AMLCG. Blood 113(17):3903-3910. doi:10. 1182/blood-2008-07-162842

68. Kam G, Yiu R, Loh Y, Ang AL, Yueh LL, Goh YT, Wong GC (2015) Impact of pegylated filgrastim in comparison to filgrastim for patients with acute myeloid leukaemia (AML) on high-dose cytarabine (HIDAC) consolidation chemotherapy. Support Care Cancer 23(3):643-649. doi:10.1007/s00520-014-2417-7

69. Bosi A, Szer J, Kassis J, Siera J, Desborough C, Buchanan K (2005) A multicenter, double-blind, randomized, phase II trial comparing pegfilgrastim with filgrastim as an adjunct to chemotherapy for acute myeloid leukemia. J Support Oncol 3(2):41-43

70. Kunivayalil SJ, Jain A, Satheesh C, Tejinder S, Lakshmaiah K, Suresh TM, Lokanatha D, Babu G (2009) A comparative study of single-dose pegfilgrastim versus daily filgrastim in patients with acute myeloid leukemia. J Clin Oncol 27 (suppl; abstr e18005)

71. Bondarenko I, Gladkov OA, Elsaesser R, Buchner A, Bias P (2013) Efficacy and safety of lipegfilgrastim versus pegfilgrastim: a randomized, multicenter, active-control phase 3 trial in patients with breast cancer receiving doxorubicin/docetaxel chemotherapy. BMC Cancer 13:386. doi:10.1186/1471-2407-13-386

72. Buchner A, Elsasser R, Bias P (2014) A randomized, double-blind, active control, multicenter, dose-finding study of lipegfilgrastim (XM22) in breast cancer patients receiving myelosuppressive therapy. Breast Cancer Res Treat 148(1):107-116. doi:10.1007/s10549014-3120-6

73. Volovat C, Bondarenko IM, Gladkov OA, Elsasser R, Buchner A, Bias P, Muller U (2015) Phase III, randomized, double-blind, placebo-controlled, multicenter study of lipegfilgrastim in patients with non-small cell lung cancer receiving myelosuppressive therapy. Spring 4:316. doi:10.1186/s40064-015-1067-7 